\title{
Contractions and Tensions: A Study of Present Difficulties Faced by Chinese Animal Documentaries and Possible Solutions
}

\author{
Tianhong LV \\ School of Journalism and Communication, Beijing 100089, China \\ 18810280446@163.com
}

Keywords: Documentary; animal; market-based reform; innovation.

\begin{abstract}
This paper analyzes the status quo of Chinese animal documentaries, classifies and researches present difficulties ranging from homogenization of the market, commentaries and creative concepts to the lack of top talents for documentary filming, and then proposes solutions to every problem discussed. Meanwhile, it reinterprets the authenticity of documentaries with the intention of seeking other prospects for animal documentaries from elements application, platforms, talents and other respects.
\end{abstract}

\section{Introduction}

According to the classification made by Zhang Tongdao, there are three types of Chinese documentaries: educative, aesthetic and industrial [1]. Educative documentaries are intended for propagating national ideology, typical of which are Concern for the People, Xi Zhongxun, and The Pillars of a Great Country. Aesthetic documentaries focus more on aesthetic and artistic features, as we can see in A Bite of China. Industrial documentaries decompose every procedure in the making of a documentary, following industrial modes and having fine division of labor as well as clear process. Chen Guoqin's Interpretation of Documentaries analyzed documentary theories and narrative by looking into specific cases [2]. In her book History of Chinese Documentary Development [3], Fang Fang went into details about Chinese documentary development from the age of shadow play to films being brought in to the year of 1983. Research Report of Chinese Documentary Development (2010-2016) by Zhang Tongdao summarized its progress annually. Previous researches on difficulties faced by Chinese documentaries and possible solutions to them mainly delved into development history and conceptual analysis. As for researches on animal documentary, emphasis was put on the humanity and technological aspects. On the basis of the researches mentioned above and by means of systematic analysis, this paper hopes to further understand and probe into issues like authenticity by taking the times into consideration.

\section{The Status Quo of Animal Documentaries}

Admittedly, Chinese documentaries fall behind the West both in technological and conceptual respects. As China has strengthened international exchanges and the government has enhanced policy support for documentary development in recent years, we have seen some outstanding documentaries around. In 2013, A Bite of China, an unexpected winner, stood out and gained a large market share by the positioning of a high market food documentary. In 2016, Born in China hit the big screen and became widely popular. It also won the Best Documentary in the 3rd Silk Road International Film Festival. Despite being a Best Documentary winner, Born in China, technically, was not a real documentary. To be exact, it was a documentary and modern film which based on real-time animal shots, followed a certain story line and was edited in post-production.

Animal World accompanied the growth of a generation and thus has engraved on our memories. When it comes to animal documentaries, Animal World which was dubbed by Zhao Zhongxiang pops out in our minds most of the time. To the surprise of most people, this series of documentaries was, in fact, introduced from abroad instead of being domestically produced. Looking back on the development of Chinese animal documentaries, there are many programs featuring animals such as 
The Great Migration of East African wild animals (2012) [4], Chinese Guide Dogs (2012), Grass and Sand (2013), and Water Villages (2014). Except for The Great Migration of East African wild animals which was shot by means of live broadcasting and impromptu interpretation, other programs centered on humans in their filming and story lines, paying more attention to humanity nature. Although there is increasing public interest in animal documentaries and a growing number of programs coming out especially after the release of Better arrange and file comprehensive channel programs in 2014 by the State Administration of Press, Publication, Radio, Film and Television of the People's Republic of China in 2013, animal documentaries which are really acknowledged and adored by the public has still been few and far between.

\subsection{Guesses About Difficulties Facing Animal Documentaries}

Aesthetic fatigue will prevent consumption, which involves a cycle of "aesthetic needs - aesthetic satisfaction - aesthetic fatigue - new aesthetic needs" [5]. Because of an enduring time lag in the market, new needs can't be satisfied when an aesthetic fatigue is still there. This is why the public have less interest in documentaries in recent years. According to a report by Chinese Broadcasts, China's documentary market is now plagued by insufficient demand and lag in idea generation, creation, production and other aspects.

\subsubsection{Aesthetic Fatigue Caused by Market Homogeneity}

Aesthetic fatigue is a common phenomenon in culture and art industry, on which Feng Xiaolun has a popular explanation: aesthetic fatigue is characterized by less excitement toward this aesthetic subject, ceased aesthetic perception and even rejection. I am more inclined to the view given by Chen Wengang in his paper On Aesthetic Fatigue, which holds that "Aesthetic fatigue is more about desire issues, closer to desire fatigue. It is noteworthy that aesthetic fatigue does not mean there is no aesthetic value. Instead it refers to the indifference caused by the subject without aesthetic value. The former one is about restraining after excitement while the later means no excitement at all" [5]. From this perspective, documentary homogeneity should take more responsibility for aesthetic fatigue.

\subsubsection{Homogeneity of Commentaries}

Against the backdrop of an unsound system of intellectual property rights and a volatile documentary market, Chinese creators are more conservative and good at intimating. Instead of pursuing innovation, they tend to take successful cases in the market as the standards for their own creation. For instance, A Bite of China bred other similar documentaries like The Tale of Chinese Medicine. We can find traces of commentaries from A Bite of China even in Born in China. Compare Bequest of the Nature (an episode name from A Bite of China) to Bequest of Autumn (an episode name from Born in China), and "Simply speaking, it is the harmonious connection between humans and the Nature." from A Bite of China to "The existence of relative strength between the positive and the negative." from Born in China.

The problem of homogeneity is no strange to animal documentaries as well. Commentaries tend to be consistent in style and are all characterized by deep and slow male voice like the Animal World dubbed by Zhao Zhongxiang. Animal World, The Valley of Wild Wolves, and Hunting have common features both in commentary style and content.

\subsubsection{Homogeneity of Creative Concepts}

From the filming of African wild animals, we can see that animal documentaries are also affected by the early from of Chinese documentaries, namely newsreel. Despite of being called animal documentaries, these programs actually focus more on humanity in their creation, centering human beings instead of animals on their storylines. For instance, Water Villages revolved round Huang Xiaowen, who engaged in animal protection for 40 years. He went over all the villages around the Inle Lake to find traces of Burmese, only to find that local people didn't know the existence of this cat. Huang Xiaowen determined to investigate reasons behind this incredible situation and found out that Burmese had disappeared from this country long time ago. So he resolved to reintroduce this cat into Burma by tracing it in Europe. With the assistance from cat-raising expert Vivian, he succeeded in breeding Burmese and eventually sent them back to Burma by cooperating with many parties. It is, therefore, evident that this program focused more on humanity than on Burmese themselves. Similar cases are Protector of Lonely Island produced by Zhang Shen in 2001(a story about a fisherman 
protecting endangered national wild animal Platalea minor at his own expense) and Ying and Bai produced by Zhang Yiqing (a story between panda keep Ying and the giant animal named Bai). They all overlooked the other character - animal.

\subsection{Lack of Top Technological Talents}

Although China's economy has seen rapid development and we have caught up with the West in hardware device, we still lag far behind them in terms of experience and technology accumulation as well as talents pooling. Compared with excellent foreign documentaries such as those produced by $\mathrm{BBC}$, Chinese documentaries are facing two evident problem, namely slow postproduction and mediocre filming aesthetic. Most of the documentaries on CNTV are no exception. In 2016, the release of Born in China brought to Chinese documentaries hopes of excellent self-produced programs coming to big screens. However, this documentary was co-produced by Britain and China and the main part of filming was not supported by Chinese technological staff. As the case stands, China not only wants more filming talents for wild animal documentaries but also lacks professional editors in this field. Unlike domestic variety shows which have progressed rapidly in editing reality show, documentary editing stays where they are.

Therefore, from the perspective of production, both current market conditions and public taste in the age of mass commercialization have exerted significant impact on animal documentaries, which explains the emergence of homogeneity and aesthetic fatigue mentioned above.

\section{Documentary Production Elements}

\subsection{Reinterpretation of Authenticity}

In documentaries there always exist conflicts between drama and authenticity. The theory of fulllength shot and Cinema de Verite (true movie) and other theories which took shape in the early days of documentary development laid the foundations for documentary authenticity later. In order to better understand today's documentaries which have further advanced, we have to reinterpret them from new perspectives and keep up with the times.

Some scholars divide documentary authenticity into three dimensions. The first dimension is to consider the authenticity of a documentary from the perspective of its creator. The authenticity we discuss here is actually relative, because creators have their own interpretation of authenticity and they constantly choose among all levels of authenticity during the creation process. The second dimension is to observe authenticity from the perspective of viewers. In other words, viewers regard whatever they see as authentic and objectively existing no matter how creators choose to present their works. The third dimension is to examine documentary authenticity and regard it as an attitude. It refers to sincere expressions of authenticity creators make based on their own understanding [6]. Take into consideration all three dimensions mentioned above, we can conclude that documentaries should not only face and present authenticity, but also take serious attitudes toward expressing and exploring it. Only in this way can there emerge more documentaries with higher levels of authenticity.

Domestic documentaries are often bounded by various abstract theories when it comes to authenticity issues. As for language style, they are confined to "omniscient and omnipotent" documentary language; in terms of idea generation, there are restrictions exerted by the traditional view of "dismissing subjective factor"; while in production, full-length shot instead of dramatic editing is favored. Limited interpretation of authenticity is to blame for these problems faced by China's documentaries.

\subsection{Aesthetics}

Just like the soul of novels is language and the soul of drama is dialogue, the soul of films and television programs is picture. Pictures underpin films and television programs in that a brilliant picture not only engender visual thrills but also bring shivers to our innermost feelings.

Aesthetic Principle (1999) defined aesthetic in this way: first, aesthetic is free and consists in creation; second, aesthetic is individual evaluation in terms of personal feeling, experience, rumination and appreciation of beauty; third, the existence of beauty is objective while aesthetic is subjective in that the latter is part of spiritual activities. As a type of film art, documentaries should pay attention to authenticity without neglecting expression artistry, aesthetic pleasure which 
authenticity brings and aesthetic requirements for filming scenes [7]. By aesthetic measures, except for A Bite of China, The Imperial Place, The Tale of Chinese Medicine and few other excellent works, most domestic documentaries still set their aesthetic standards against newsreels and the Animal World.

\subsection{Humanity}

Traditional Chinese documentaries have always advocated original recording. Ying and Bai which was directed by Zhang Yiqing came under fire from theorists and other directors the moment it was released in 2001. From modern perspective, it is an excellent documentary beyond doubt, though. As long as the three dimensions of authenticity remain unaffected, a documentary can bring viewers psychologically closer to it by presenting the creator's attitudes. During the process of filming and editing, those scenes which reflect themes need accenting and creators' attitudes should be presented.

\subsection{Drama}

Compare to documentaries, movies always attract audience more and there I a good chance of boxoffice success. When it comes to movies, story is the first to pop up in people's mind. It is the suspense and conflicts of a story that encourage audience to continue to the end. We may as well draw lessons from the "striking point" of movies, namely drama, to create documentaries [8].

Drama comes from conflicts. During the initial filming period, priorities should go to accumulate special events and scenes, which will lay the foundations for dramatic editing in post-production. The key to creating dramatic situations in post-production lies in the timing of documentaries. Fast pace will spiritually exhaust the audience while slowing down will make programs seem boring. So a good documentary should on the whole have good timing of editing, which means slowing down when it is emotional and pacing up when it presents conflicts. Appropriate arrangement of these slots largely determines whether a documentary will catch on or not.

\section{Prospects for Animal Documentaries}

As for commentaries, Chinese animal documentaries have always kept objective and rational in tone. However, such impersonal commentaries will only widen an already existing distance between wild animals and viewers. As a result, viewers can hardly establish emotional contact with these documentaries and thus have less and less interest in them. To deal with this problem, we may as well structure a "social environment" for animals just like ours by personifying animals and giving them names. Take Born in China as an example, it named a snow leopard as Dava, which somehow closed the distance between the audience and the character Dava and made them sympathetic towards her fate. This is why there were many viewers blowing their noses when a scene indicated that Dava was gone. Once emotional contact is in place, it will be much easier to bring audiences into where the documentary character is by setting conflicts and suspense.

\subsection{Application of Producing Elements \\ 4.1.1 Three-Dimensional Authenticity}

Authenticity is relative and pure authenticity is unattainable. Behind the inauthentic authenticity of documentaries, we can see the intentions of film makers. Intentions determine the level of authenticity. In other words, all authenticity is mixed with artificial creation. Concretely, producer's intention plays a crucial role in documentary production. For example, Zhang Yiqing had complex intentions in Ying and Bai. His intention of making loneliness its theme was to show that humans, like pandas, were socially lonely. Therefore, when editing, Zhang Yiqing selected those clips which could express his ideas based on his own interpretation of documentary authenticity. This is also why at that time his documentary stood out from many similar works, has been popular since then and eventually become a classic case. We can see from here that creators should never firmly confine themselves to conventional filming and editing methods or restrictions set by traditional definitions of authenticity. Instead, they should clarify their intentions and feel free to express their opinions on condition that authenticity from three dimensions mentioned above is all in place. 


\subsubsection{Aesthetics}

The aesthetics of scenes can be perceived in five aspects. First, meeting the basic requirements of a scene which include being flat, stable, precise, even and clear. This will help present the aesthetic and artistry of a scene.

Second, composition matters. The overall composition of A Bite of China was between "documentary style" and "expressive style" [9]. It is true that the scene of a man digging lotus root in a boat impressed many viewers. The same goes for a scene in Born in China when the golden monkey Taotao sat alone on a tree after being rejected by his father. There thus appeared sharp contrast between Taotao's loneliness and all family huddled up to warm each other later by the use of blankleaving.

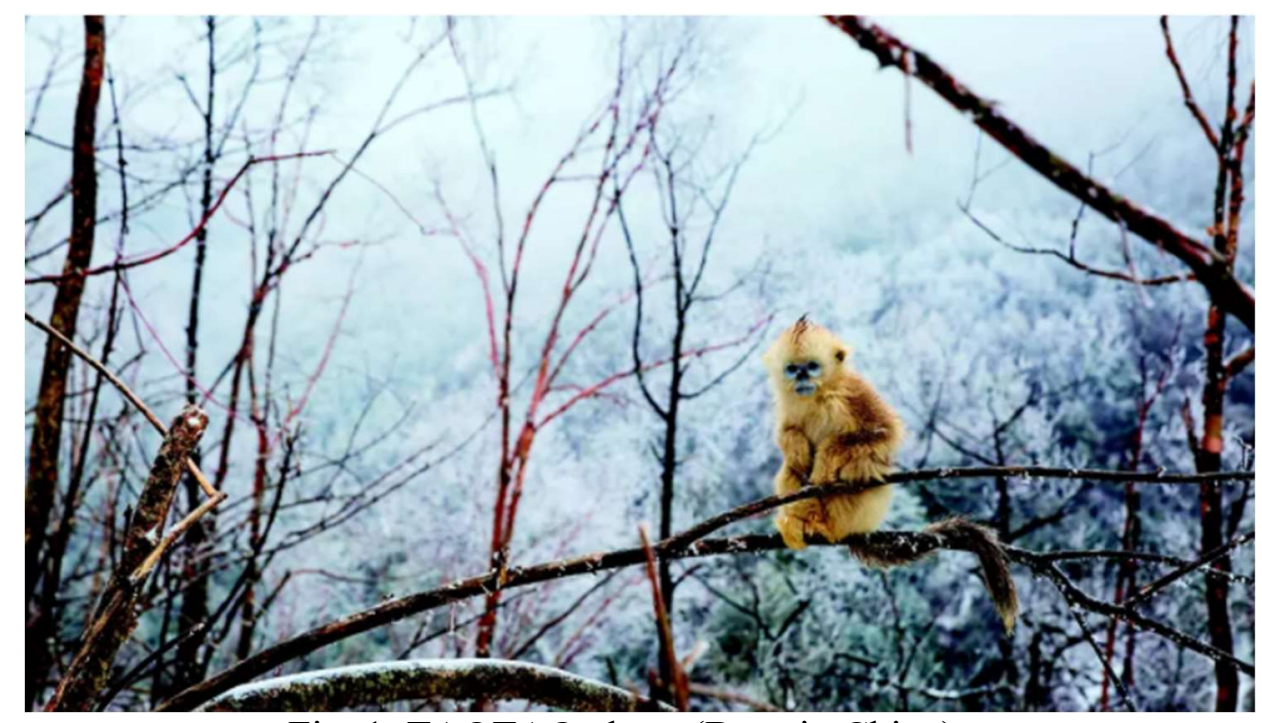

Fig. 1. TAOTAO along (Born in China)

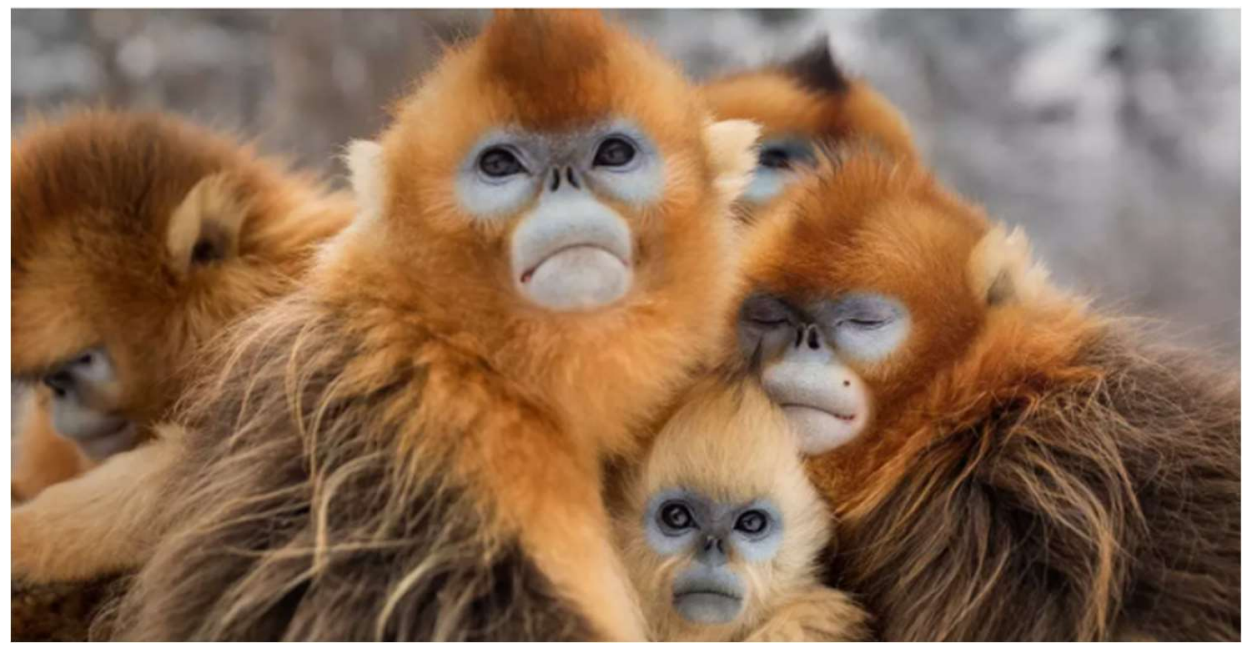

Fig. 2. TAOTAO with family (Born in China)

Third, filming requires subtle gradations of light and shade. In Born in China, there were pictures of red-crowned crane singing and facing upward shot with back-light and pictures of golden monkeys with their golden lines shining in the sun. In Mitsuaki Iwagos World Catwalk, back-lighting was used to film the scene of cats yawning and exhaling. The white air exhaled by cats can show the cold outside and augment the aesthetic of that very moment. 


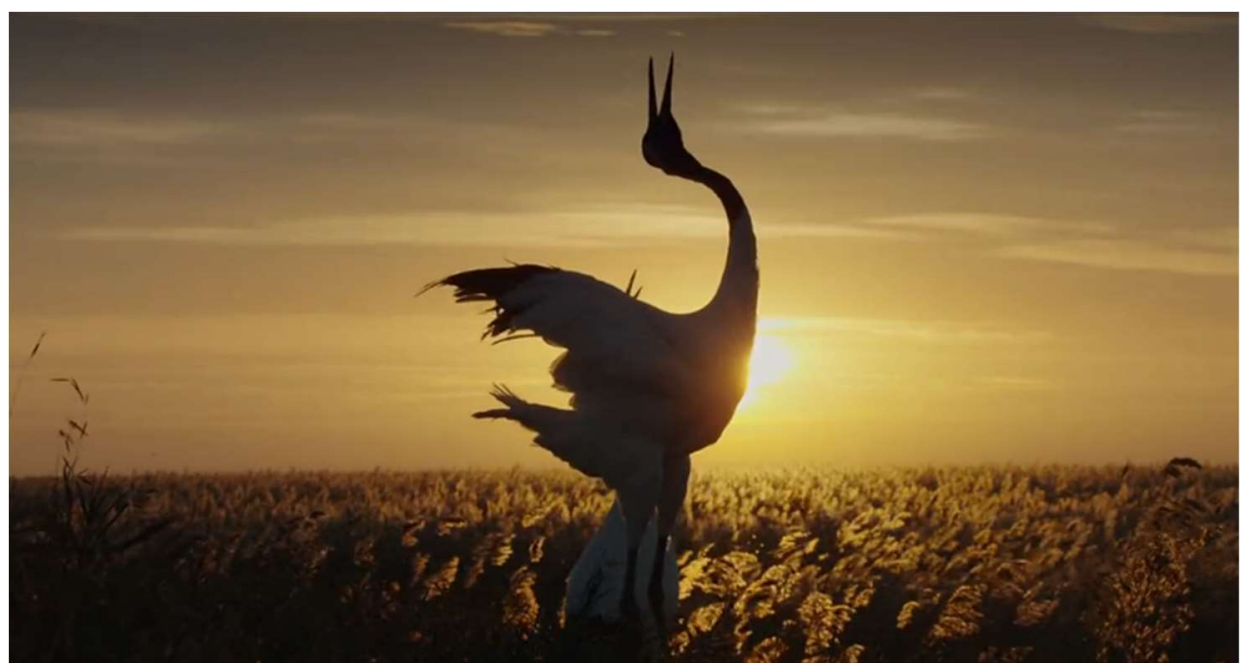

Fig. 3. red-crowned crane (Born in China)

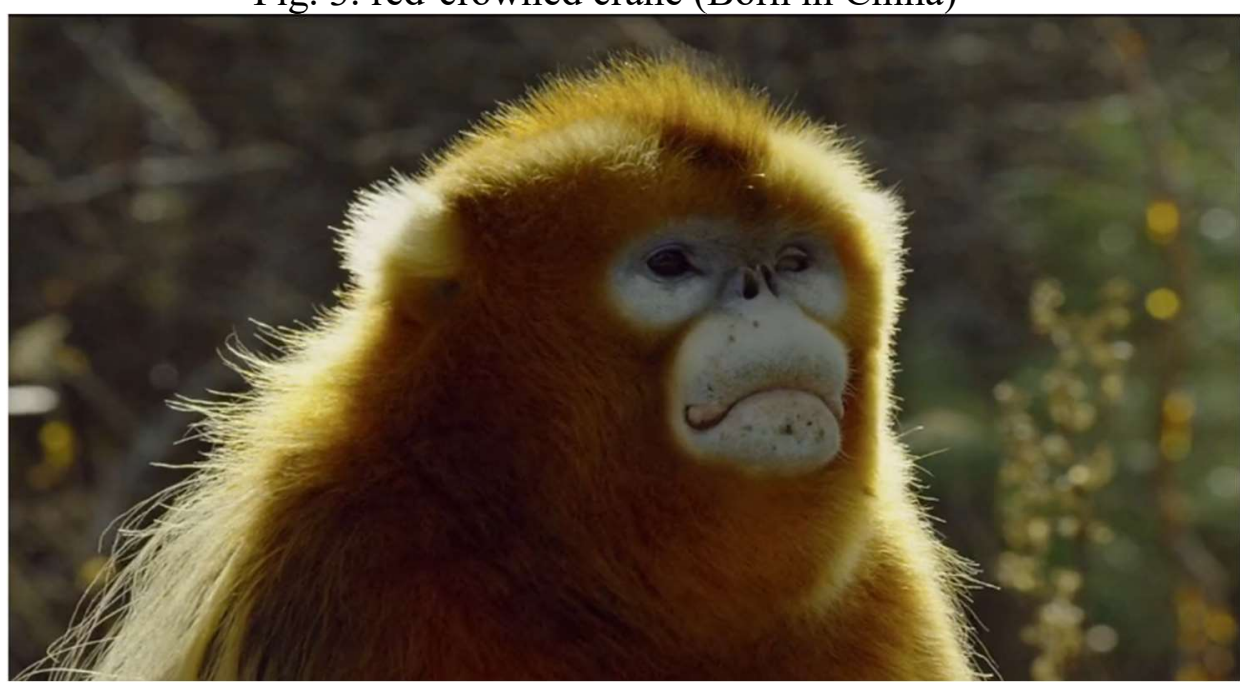

Fig. 4. golden monkey (Born in China)

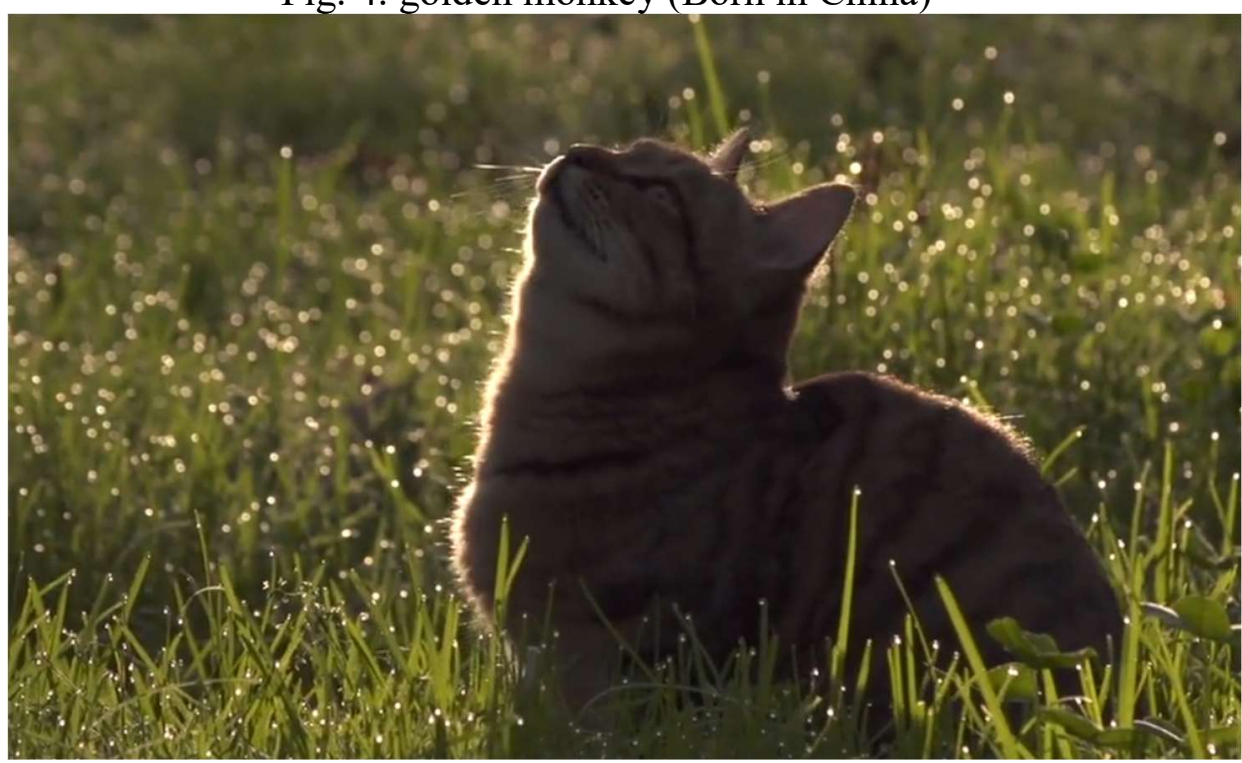

Fig. 5. cat yawning (Mitsuaki Iwagos World Catwalk)

Fourth is about the changeability of shots. Conventional documentary filming usually adopts regular angle views and shots. However, it is special filming methods such as close-up, panorama, time-lapse and high-speed photography, macrophotography and aerial photography that visually impress audiences more and feast their eyes on novel photography via "less familiar" visual angles. A bite of China employed these skills to shoot most of the food in it [10]. 
Fifth is about accumulating more natural scenes and looking for aesthetics among the "less familiar", which is a common feature shared by many excellent documentaries. For example, those magnificent opening scenes of Planet Earth immediately caught viewers' attention.

To sum up, the aesthetic of documentaries severs to attract audiences and impress them in a direct and appealing way, which works well in terms of stressing themes and conveying emotions. At this time when everything advances rapidly and everyone moves fast, this visual aesthetic is more likely to find favor with the public.

\subsubsection{Humanity}

The humanity we discuss here is mainly on commentaries. Audiences are much more sensible than we think, especially those who sit in a cinema. Documentary commentaries always sound authoritative and indifferent both at home and abroad. So, we may as well change these commentaries into more lively versions. One is to give up using commentaries, like Zhang Yiqing' did to Ying and Bai. Another is to employ vivid and heart-warming commentaries like those in the appealing and lovely Japanese documentary Mitsuaki Iwago's World Catwalk which recorded cats across the world. And a third way is to adopt unusual commentaries as we have seen in Born in China. It was dubbed by Zhou Xun who not only commented on animal behavior but also tried to figure out animal emotions base on their behavior, which enabled commentaries to reflect their external behavior and to penetrate into internal feelings at the same time, thus impressing viewers.

However, it will seem unnatural and inauthentic if commentaries purely strived for drama and loveliness instead of commenting subjectively based on studies of animal behavior and psychology. Although Born in China is a film about animal, it has many aspects worth of learning for documentaries if we regard it as a documentary. However, it also has some unduly subjective commentaries which may backfire. For example, commentary at the 27 th minute was "It convinces Meimei that he was her god, her idol." It is definite that pandas have no idea about the so-called god or idol. This subjective assumption of a panda's thoughts was a violation of expressional authenticity. Clips like this will make viewers feel tricked, thus losing appeals.

\subsubsection{Drama}

The unfamiliarity between wild animals and viewers will be even widened by commentaries that sound authoritative and objective. This makes it harder for viewers to sympathize with documentary characters, which explains there is less and less public interest in animal documentaries. Therefore, we may as well structure a "social environment" for animals just like ours by personifying animals and giving them names. Take Born in China as an example, it named a snow leopard as Dava, which somehow closed the distance between the audience and the character Dava and made them sympathetic towards her fate. This is why there were many viewers blowing their noses when a scene indicated that Dava was gone. Once emotional contact is in place, it will be much easier to bring audiences into where the documentary character is by setting conflicts and suspense.

\subsection{Pooling Talents}

Compared with universities which offer systematic education, vocational schools where students receive training to be professional talents are less valued by Chinese society. This explains why there are a great number of "Jacks of all trades" in the market while technological talents who speacialize in one area are rare.

Therefore, the field of documentary should pay attention to pooling talents. For one thing, policy support is needed to train specialized talents; for another, we should follow international market by bringing in advanced technology and ideas and strengthening cooperation and exchanges with other countries. As documentary has been revived recently, more and more talents with relevant skills will approach this industry and adjust themselves to become technological talents to further advance documentary development.

\subsection{Dragging and Driving Forces in Commercialization-Convention Plus the Internet}

As mentioned above, commercialization homogenizes commentaries, filming and business models of documentaries, resulting in problems like following suit, aesthetic fatigue and lack of innovation. All these are dragging forces commercialization has exerted on documentary development. Under theis circumstances, it is essential to figure out how to turn dragging forces into driving ones. 
New media today moves so fast that there are no longer just televisions and cinemas for people to choose. The development of television is declining, because TVs will become less and less appealing to the public as digital natives grow up. In contrast, the Internet is moving full speed ahead and offers entertainment to users at much lower costs. As a result, the costs of serving people in the front end in the theory of long tail are closing to that of serve those in the middle to back end, which suggests shifting targets towards the middle to back end. But here in China, network users are less conscious of intellectual property rights and get used to enjoying free services rather than paying to obtain them. So it is unwise to circulate documentaries on line at the outset. Instead, cinemas are the best choice to distribute new documentaries, build reputation and recoup initial investment for the first time. After reputation is in place, some investment can then be recouped by selling broadcasting rights to provincial satellite television stations. However, broadcasting documentaries on TV has time limits, which surely cannot reach most of their potential viewers. That's why we need another phase to recoup investment for the third time, namely uploading documentaries onto new media platforms on line and charging fees for watching. In the end when the heat of a documentary cools down, it should be open to all for free in order to attract prospect audiences for the next documentary in production.

\section{Contraction and Tension}

Because of the limitation of length, this paper mainly researches familiar documentaries on the market which are sourced from CNTV and thus covers less works from regional niche market. Meanwhile, general analysis is adopted here for research, so explanations for each part may not be detailed. These two are the shortcomings of this paper.

In summary, Chinese documentary development is gaining momentum as globalization runs deep. We have to admit, however, that we still have a long way to go before we can compete with worldwide excellent documentaries because of those long-standing counterproductive effects exerted by traditional experience and ideas of production and the existing films and television programs system. This explains the emergency of both contractions and tensions in documentary filming. Contractions refer to various limitations, especially those in the aspects of market, talents, and film production system. And tensions lie in areas such as conception and technology which remain to be improved. Documentary production should work to employ both traditional cinemas and new media online, combine commercialization with artistry in a brave way, and reinterpret and reposition authenticity. Concretely, styles of commentaries can be innovated by using humane words; documentaries can involve more dramas; in the long term, it pays to establish a scientific talent training system and a legal system to protect idea generation and application. All this goes a long way towards upgrading the documentary quality.

\section{References}

[1]. Zhang Tongdao. \& Liu Lan. 2014 Report of Chinese Documentary Development—Review on Film Creation Part of Chinese Documentaries [J]. Hundred Schools in Arts, 2014, 30(3): 15-20.

[2]. Interpretation of Documentaries [M]. Fudan University Press, 2007.

[3]. Fang Fang. History of Chinese Documentary Development [M]. China Theatre Press, 2003

[4]. The Great Migration of East African wild animals (2012) was a live program about African wild animals broadcasted by CCTV for the first time in the world, which unfolded panoramic views of the unique natural wonder and offered Chinese viewers a chance to get close to "the greatest life migration" on Earth.

[5]. Chen Wengang. On Aesthetic Weariness [J]. Journal of Hubei Institute for Nationalities (Philosophy and Social Sciences), 2005, 23(5): 32-36.

[6]. Xie Hou. Analysis of Different Dimensions of Authenticity-Take BBC Nature Documentaries as an Example [J]. Media Time, 2012, 8: 021. 
[7]. Zhu Liyuan. \& Jiang Kongyang. Aesthetic Principle [J]. 1999.

[8]. Yang Qiujun. Application of Drama in Documentaries [J]. Voice \& Screen World, 2007 (6): $45-$ 45.

[9]. Zhou Chunhui, Freehand and Emotional conveying: Audio-visual Language Presenting Documentary Aesthetics_-Take 'A Bite of China' as an Example [J]. Movie Review, 2012 (19): 99-101.

[10]. Liu Tao. \& Han Hong. \& Xu Bin. Television Documentary Creation Under the theory of Defamiliarization -Exploring the Factors for the Success of 'A Bite of China' [J]. Movie Review, 2013 (1): 71-74. 